\title{
EFEITO DO PROCESSAMENTO DO MILHO SOBRE O DESEMPENHO E COMPOSIÇÃO DE CARCAÇA DE PIABA (Leporinus friderici) CRIADA EM TANQUES-REDE
}

\author{
Effect of the corn processing in the performance and carcass composition \\ of the piaba (Leporinus friderici) in the cage farm
}

\author{
Jodnes Sobreira Vieira ${ }^{1}$, Priscila Vieira Rosa Logato ${ }^{2}$, Paula Adriane Perez Ribeiro ${ }^{3}$, \\ Rilke Tadeu Fonseca de Freitas ${ }^{4}$, Elias Tadeu Fialho ${ }^{5}$
}

\begin{abstract}
RESUMO
Com este experimento objetivou-se verificar os efeitos dos processamentos do milho sobre o desempenho e composição de carcaça de piaba (Leporinus friderici) criada em tanques-rede. Foi conduzido na Usina Hidrelétrica da Companhia Energética de Minas Gerais (CEMIG), município de Itutinga, com duração de 45 dias. Foram utilizados 24 tanques-rede de $1 \mathrm{~m}^{3}$, com 480 alevinos. O delineamento foi em blocos casualizados, com 4 tratamentos (rações formuladas com milho moído, extrusado, laminado e peletizado) e 3 repetições. Os dados foram submetidos à análise de variância e as médias dos tratamentos, comparadas pelo teste Scott \& Knott. Os resultados não mostraram diferença significativa para os parâmetros de desempenho (peso final médio, consumo aparente de ração médio, conversão alimentar aparente, ganho de peso total médio, ganho de peso diário médio) ( $\mathrm{P}>0,05)$, porém, o milho extrusado e o moído aumentaram o teor de proteína $(\mathrm{P}<0,05)$ e diminuíram o teor de gordura da carcaça $(\mathrm{P}<0,05)$. Conclui-se que o processamento do milho não melhora o desempenho dessa espécie, mas com os milhos moído e extrusado, há uma melhor utilização da proteína para fins estruturais.
\end{abstract}

Termos de indexação: ingrediente, nutrição, peixe, amido.

\begin{abstract}
The experiment with the objective of verify the effects of the processing (extrusion, rolling and pelleting of corn) on the performance and composition of the Piaba (Leporinus frederici) carcass, was conducted in the Usina Hidreletrica da Companhia Energética de Minas Gerais - CEMIG (Minas Gerais Hydroelectric Station), in the Itutinga- MG, with the lenght of 45 days. The experiment was undertaken in 24 cages of $1 \mathrm{~m}^{3}, 480$ fingerlings were utilized, they were distributed into blocks. The four experimental rations were formulated based in corn meal, extruded corn, rolled corn and pelleted corn. The data obtained were submitted to the analysis of variance and the comparison of means of the treatments by the Scott \& Knott test. The results showed any statistical difference in the performance parameters. However, the use of extruded corn and corn meal increased protein content $(\mathrm{P}<0.05)$ and decreased fat content $(\mathrm{P}<0.05)$ of the carcass traits, these results showed, improved protein utilization for structural purposes. In conclusion the corn processing did not improve the performance of the fish and that corn meal and extruded corn increased protein content and reduced fat content in the carcass.
\end{abstract}

Index terms: ingredient, nutrition, fish, starch.

(Recebido para publicação em 8 de agosto de 2003 e aprovado em 30 de Janeiro de 2004)

\section{INTRODUÇÃO}

Atualmente as atividades agropecuárias têm tido grande destaque na economia mundial entre elas, a piscicultura apresenta índices de crescimento superiores às demais atividades rurais. Em conseqüência, há um maior interesse em se investir na nutrição dos animais, visando uma melhor performace produtiva e econômica na criação. Os custos com alimentação representam aproximadamente $60 \%$ a $70 \%$ num sistema de criação intensivo e, por isso, torna-se necessária a preocupação com a formulação de rações balanceadas que permitam melhor assimilação de nutrientes pelos peixes, conferindo uma carcaça com maior teor de proteína e menor teor de gordura.

Entre alguns nutrientes de relevância na nutrição, os carboidratos representam uma preocupação para a piscicultura, uma vez que seu aproveitamento é bastante variável em função do hábito alimentar, clima da região, tipo de carboidrato e forma como é processado.

1. Doutorando em Zootecnia da Universidade Federal de Lavras/UFLA - Caixa Postal 3037 - 37200-000 - Lavras, MG

2. Professora Adjunta do Departamento de Zootecnia da Universidade Federal de Lavras/UFLA.

3. Mestranda em Aqüicultura da Universidade Federal de Lavras/UFLA.

4. Professor Titular do Departamento de Zootecnia da Universidade Federal de Lavras/UFLA

5. Professor Titular do Departamento de Zootecnia da Universidade Federal de Lavras/UFLA. 
Os carboidratos constituem o grupo de nutrientes mais contraditórios dentro da alimentação dos peixes. Shimeno et al. (1977) desenvolveram estudos comparativos do metabolismo de carboidratos de uma espécie estritamente carnívora (Seriola quinqueradiata, Caragidae) e outra de hábito herbívoro (Cyprinus carpio, Cyprinidae Linnaeus, 1758) e constataram que a carnívora apresentou baixa capacidade para digerir e utilizar carboidratos da dieta.

O uso relativo dos carboidratos pelos peixes parece estar associado à complexidade de sua molécula. Certas espécies utilizam tanto açúcares simples quanto açúcares complexos, enquanto outras não utilizam nem mesmo os açúcares simples como fonte de energia (SULLIVAN \& REIGH, 1995). Hilton \& Atkinson (1982), trabalhando com truta arco-íris (Oncorhynchus mykiss Walbaum, 1792), observaram que os peixes carnívoros de água temperada não aproveitam carboidratos complexos. A capacidade de utilização de carboidratos complexos pode estar relacionada à temperatura de cultivo. Peixes de clima temperado têm uma menor capacidade de utilizar carboidratos mais complexos, enquanto peixes tropicais os utilizam como uma maior eficiência. Esse fenômeno pode ser esperado, pois o equilíbrio insulina/glucagon é termo-sensível, ou seja, em peixes de clima temperado, a liberação de glucagon aumenta e a de insulina diminui, ao contrário do que ocorre com peixes tropicais, como observado por Umminger (1978).

Wilson (1994) observou que a utilização relativa dos carboidratos pelos peixes pode estar associada também a fatores, como: baixa atividade da hexoquinase ou falta da glicoquinase, possível inibição na liberação de insulina pela somatostatina ou ao baixo número de receptores para insulina nessas espécies.

Embora os peixes não tenham exigências dietéticas específicas para carboidratos, a inclusão desse nutriente na formulação das dietas constitui uma importante fonte de energia, representando uma considerável economia na produção de rações, uma vez que apresentam menor custo em relação aos alimentos protéicos (GATLIN, 1999).

Wilson (1994) verificou que os dissacarídeos e polissacarídeos digestíveis favorecem mais acentuadamente o crescimento que os monossacarídeos, assim como o amido cozido ou gelatinizado possui uma melhor digestibilidade e influencia mais acentuadamente o crescimento dos peixes que o amido cru. A presença de amido cru na dieta mostrou-se inadequada para ser utilizada na alimentação dos peixes, independentemente de seu hábito alimentar (carnívoro, onívoro ou herbívoro).
Dessa forma, torna-se necessário manipulá-lo tecnologicamente, de tal maneira que aumente a área de contato com as enzimas, o que é conseguido com tratamento térmico.

O processamento adequado pode melhorar a digestibilidade do amido. Entre os processamentos de ração mais utilizados na aqüicultura, estão a extrusão e a peletização, os quais propiciam modificações benéficas do amido cru, melhorando, assim, o aproveitamento nutricional das rações pelos peixes (JAYARAM \& SHETTY, 1981).

A extrusão é uma tecnologia relativamente nova que exige alta pressão (30 a $60 \mathrm{~atm}$ ), umidade e temperaturas entre 130 e $150^{\circ} \mathrm{C}$, causando expansão da mistura de ingredientes e gelatinização do amido. Assim, ocorre exposição dos nutrientes contidos no interior das células vegetais, favorecendo a ação digestiva e melhorando a eficiência alimentar dos peixes (KUBITZA, 1998).

A peletização consiste em compactar mecanicamente a ração dentro de uma câmara de prensagem, na qual rolos compressores forçam a passagem da mistura dos ingredientes que compõem a mesma através de orifícios existentes em um anel externo chamado de matriz (COELHO, 1997). Toda matéria-prima utilizada no processo passa por um aquecimento, seja pelo uso prévio de vapor com temperaturas em torno de $120^{\circ} \mathrm{C}$, elevando a temperatura da mistura para uma faixa entre 50 a $90^{\circ} \mathrm{C}$, seja pelo atrito mecânico sofrido durante a prensagem da ração pelos rolos compressores contra a matriz, elevando a temperatura da mistura para 50 a $60^{\circ} \mathrm{C}$ (MILLÁN et al., 1987).

Esse procedimento propicia uma maior uniformidade à ração e melhor aceitação dos ingredientes da mistura, diminuindo a seletividade alimentar e reduzindo as perdas por lixiviação de nutrientes. Possibilita, ainda, a destruição parcial de alguns fatores antinutricionais, aumentando a eficiência alimentar (KUBITZA, 1998; PEZZATO, 1997).

Segundo alguns autores, o melhor aproveitamento de carboidratos em rações contendo ingredientes extrusados é devido ao aumento da taxa de amido gelatinizado nas rações. Isso foi observado por Takeuchi et al. (1990) quando compararam alevinos de truta (Orncorhynchus mykiss Walbaum, 1792) e carpa (Cyprinus carpio Linnaeus, 1758) para observar a disponibilidade de ingredientes com fontes de carboidrato (amido de batata, amido de milho, farinha de trigo, milho e centeio) extrusados ou não. Observaram que, em ambas as espécies, o crescimento e as taxas de eficiência alimentar e eficiência protéica foram maiores em 
peixes alimentados com rações contendo ingredientes extrusados, quando comparadas com rações que continham ingredientes não-extrusados. Porém, rações formuladas com farinha de trigo, quando submetidas aos dois tratamentos, não mostraram diferença no desempenho dos peixes.

O Leporinus friderici, conhecido popularmente como piava, piaba, piau-de-três-pintas ou simplesmente piau, é uma espécie encontrada na bacia dos rios Paraíba, Mogi-Iguaçu, Pardo, Grande, Piracicaba, Paraná e rios da bacia Amazônica e do nordeste brasileiro. Alimenta-se de insetos e vegetais e é uma espécie bastante apreciada na pesca esportiva (NOMURA, 1984).

Dessa forma, realizou-se este experimento objetivando avaliar os efeitos de diferentes processamentos do milho sobre o desempenho e a composição de carcaça de piaba (Leporinus friderici Bloch, 1794) criada em tanques-rede.

\section{MATERIAL E MÉTODOS}

O experimento foi conduzido no reservatório da Usina Hidrelétrica da Companhia Energética da Minas Gerais (CEMIG), no município de Itutinga - MG. O período experimental, do dia 07 de novembro ao dia 21 de dezembro de 2000, foi precedido por uma fase de adaptação dos animais, entre os dias 23 de outubro e 06 de novembro. Os alevinos, oriundos de desova induzida em laboratório, foram provenientes da Estação de Hidrobiologia e Pesquisa de Três Marias - MG (CODEVASF). Foram estocados 900 alevinos na Estação de Hidrobiologia e Piscicultura do Departamento de Zootecnia da Universidade Federal de Lavras - MG, por um período de 5 meses, sendo alimentados com ração comercial contendo 36\% de proteína bruta e 3000 kcal de energia digestível (ED)/ Kg. Foram selecionados 480 alevinos em função do peso. O arraçoamento foi feito 3 vezes ao dia ( 8 ; 12 e 17 horas).

Utilizaram-se 24 tanques-rede circulares, com 1,10 m de diâmetro x 1,3 m de altura, permanecendo aproximadamente $20 \mathrm{~cm}$ fora da lâmina d'água, o que totalizou um volume útil de $1 \mathrm{~m}^{3}$. Os tanques foram montados numa plataforma flutuante, submersos na região do epilímnio. A plataforma foi instalada próxima à barragem com uma profundidade média de $4 \mathrm{~m}$.

Os tratamentos, representados por 4 rações isométricas (32,85\% de PB e $2883 \mathrm{kcal}$ de ED/kg), diferenciaram-se entre si apenas no ingrediente milho, como ilustrado na tabela 1 .

A composição química dos ingredientes e as exigências nutricionais para espécies onívoras foram baseadas, respectivamente, em dados de Fialho (1997) e NAS/NRC (1993). A ração, após misturada e homogeneizada, foi prensada a seco em uma peletizadora (peneira de $3 \mathrm{~mm}$ ), obtendo-se, assim, grânulos entre 3 e $5 \mathrm{~mm}$ de comprimento. A temperatura durante 0 processo de peletização foi, em média, de $52^{\circ} \mathrm{C}$, fora da peletizadora.

A cada biometria, a quantidade de ração foi reajustada a 5\% do peso vivo/ repetição. Os comedouros foram adaptados para recolherem as sobras, sendo utilizadas duas bacias plásticas com diâmetros diferentes, de 50 e $20 \mathrm{~cm}$, montadas uma dentro da outra. Os peixes de cada unidade experimental foram amostrados e pesados no $1^{\circ}, 15^{\circ}, 29^{\circ}, 45^{\circ}$ dia, sendo a porcentagem média de peixes amostrados nas três primeiras pesagens de $40 \%$ e na última pesagem $100 \%$ dos peixes amostrados.

As temperaturas ambiente, máxima e mínima foram registradas diariamente pela manhã, por meio de um termômetro de máxima e mínima. A temperatura e o teor de oxigênio dissolvido (OD) da água dos tanques foram obtidos diariamente, durante os horários de alimentação, por meio de um oxigenômetro digital portátil (YSI 55). O pH e a transparência da água do tanque foram determinados semanalmente, durante o período experimental, utilizando o medidor de pH F-1002 e um disco de Secchi de 26,5 cm de diâmetro para avaliação da transparência da água.

Os parâmetros utilizados para a avaliação de desempenho dos diferentes tratamentos foram: Peso final médio $\left(\mathrm{PFM}=\right.$ Peso final total $/ \mathrm{N}^{0}$ total de peixes); Consumo aparente de ração médio (CARM = Consumo de ração total/ $\mathrm{N}^{0}$ total de peixes); Conversão alimentar aparente (CAA = Quantidade de alimento consumido/ Ganho de peso médio); Ganho de peso total médio (GPTM = Peso final médio - Peso inicial médio); Ganho de peso diário médio (GPDM = GPTM/ 45 dias). A composição da carcaça foi determinada mediante a avaliação de parâmetros estabelecidos pela AOAC (1990), tais como: umidade, proteína, gordura e cinzas.

O delineamento experimental utilizado foi o de blocos casualizados, com 4 tratamentos e 3 repetições, e cada bloco foi composto por 12 unidades experimentais (3 repetições/ tratamento), tendo um total de 2 blocos e 24 unidades experimentais.

Para as análises estatísticas, foi utilizado o programa SISVAR (Sistema de Análises Estatísticas), proposto por Ferreira (2000), sendo as médias dos tratamentos comparadas pelo teste de agrupamento univariado de Scott \& Knott, ao nível de 5\% de significância. 
VIEIRA, J. S. et al.

TABELA 1 - Composição percentual dos ingredientes das rações experimentais.

\begin{tabular}{|c|c|c|c|c|}
\hline \multirow{2}{*}{ Ingredientes (\%) } & \multicolumn{4}{|c|}{ Tipos de processamentos do amido de milho } \\
\hline & Moído & Extrusado & Laminado & Peletizado \\
\hline Farinha de peixe & 14,34 & 14,34 & 14,34 & 14,34 \\
\hline Farelo de Soja & 36,63 & 36,63 & 36,63 & 36,63 \\
\hline Farelo de Trigo & 15,00 & 15,00 & 15,00 & 15,00 \\
\hline Farelo de Milho & 28,68 & - & - & - \\
\hline Milho Extrusado & - & 28,68 & - & - \\
\hline Milho Laminado & - & - & 28,68 & - \\
\hline Milho Peletizado & - & - & - & 28,68 \\
\hline Caulim & 3,78 & 3,78 & 3,78 & 3,78 \\
\hline Fosfato monoamônio & 1,37 & 1,37 & 1,37 & 1,37 \\
\hline Suplemento Vitamínico ${ }^{(1)}$ & 0,10 & 0,10 & 0,10 & 0,10 \\
\hline Suplemento Mineral ${ }^{(2)}$ & 0,10 & 0,10 & 0,10 & 0,10 \\
\hline TOTAL & 100,00 & 100,00 & 100,00 & 100,00 \\
\hline Proteína Bruta (\% PB) & 32,80 & 32,80 & 32,80 & 32,80 \\
\hline Energia Dig. (kg/g PB) & 2882,70 & 2882,70 & 2882,70 & 2882,70 \\
\hline Fibra Bruta (\%) & 5,03 & 5,03 & 5,03 & 5,03 \\
\hline Extrato Etéreo (\%) & 3,68 & 3,68 & 3,68 & 3,68 \\
\hline Cálcio (\% Ca) & 1,03 & 1,03 & 1,03 & 1,03 \\
\hline Fósforo Disponível (\% Pd) & 0,56 & 0,56 & 0,56 & 0,56 \\
\hline
\end{tabular}

(1) Composição por quilo de suplemento (quantidade por quilo de premix): Vitamina A, 1500 U.I; Vitamina B, 20 mg; Vitamina $B_{2}, 15$ mg; Vitamina $B_{3}$, 1000 U.I; Vitamina $B_{12}$, 10 mg, 1000 U.I; Vitamina E, 25 mg; Vitamina PP, 120 mg; Colina, 2000 U.I; Pantotenato de Cálcio, 80 mg; Ácido fólico, 2 mg; BHT, 170 mg.

(2) Composição por quilo de suplemento (quantidade por quilo de premix): Manganês, 80 mg; Ferro, 24 mg; Zinco, 50 mg; Cobre, 8 mg; Iodo, 3 mg; Selênio, 0,1 mg; BHT, 170 mg.

O modelo adotado para análise dos dados foi:

$$
\mathbf{Y}_{\mathrm{ijk}}=\mu+\mathbf{t}_{\mathbf{i}}+\mathbf{b}_{\mathbf{j}}+\mathbf{e}_{\mathrm{ij}} \text {, Em que: }
$$

$\mathrm{Y}_{\mathrm{ij} \mathrm{k}}=\mathrm{O}$ valor observado no tratamento $\mathrm{i}$ no bloco $\mathrm{j}$ da repetição k;

$\mu$ = Média geral do experimento;

$t_{i}=$ Efeito do tratamento $i$, com $i=1,2,3,4 ;$

$\mathrm{b}_{\mathrm{j}}=$ Efeito do bloco j, com $\mathrm{j}=1,2$;

$\mathrm{e}_{\mathrm{ij}}=\mathrm{O}$ erro experimental associado a $\mathrm{y}_{\mathrm{ij}}$ que, por hipótese, tem distribuição normal com média $\mu=0$ e variância $\sigma^{2}$.

\section{RESULTADOS E DISCUSSÃO}

O resumo das análises de variância para ganho de peso diário médio (GPDM), ganho de peso total médio (GPTM), ganho de peso final médio (GPFM), consumo aparente de ração médio (CARM) e conversão alimentar aparente (CAA) são apresentados na Tabela 2. Esses dados, submetidos à análise de variância, não revelaram efeitos estatisticamente significativos para os tratamentos $(\mathrm{P}>0,05)$. 
Efeito do processamento do milho sobre o desempenho e composição...

TABELA 2 - Efeito dos tratamentos sobre o desempenho da piaba (Leporinus friderici).

\begin{tabular}{lccccc}
\hline & \multicolumn{5}{c}{ Tratamento $^{\mathbf{1}}$} \\
\cline { 2 - 6 } & Milho Moído & Milho Extrusado & Milho Laminado & $\begin{array}{c}\text { Milho Peletiza- } \\
\text { do }\end{array}$ & CV\% \\
\hline GPDM (g) & $0,69 \mathrm{a}$ & $0,68 \mathrm{a}$ & $0,70 \mathrm{a}$ & $0,73 \mathrm{a}$ & 11,12 \\
GPTM (g) & $31,12 \mathrm{a}$ & $30,57 \mathrm{a}$ & $31,66 \mathrm{a}$ & $32,90 \mathrm{a}$ & 11,12 \\
GPFM (g) & $44,75 \mathrm{a}$ & $45,31 \mathrm{a}$ & $45,97 \mathrm{a}$ & $47,18 \mathrm{a}$ & 7,76 \\
CARM (g) & $71,20 \mathrm{a}$ & $69,92 \mathrm{a}$ & $71,24 \mathrm{a}$ & $71,54 \mathrm{a}$ & 6,96 \\
CAA (g) & $2,29 \mathrm{a}$ & $2,30 \mathrm{a}$ & $2,27 \mathrm{a}$ & $2,18 \mathrm{a}$ & 5,41 \\
\hline
\end{tabular}

${ }^{1}$ Médias seguidas de letras iguais, na mesma linha, não diferem entre si pelo teste de Scott e Knott ao nível de 5\% de significância.

TABELA 3 - Efeito dos tratamentos sobre composição de carcaça da piaba (Leporinus friderici).

\begin{tabular}{cccccc}
\hline & \multicolumn{4}{c}{ Tratamento $^{\mathbf{1}}$} \\
\cline { 2 - 6 } & $\begin{array}{c}\text { Milho } \\
\text { Moído }\end{array}$ & $\begin{array}{c}\text { Milho } \\
\text { Extrusado }\end{array}$ & Milho Laminado & Milho Peletizado & CV\% \\
\hline Umidade (\%) & $68,93 \mathrm{a}$ & $68,51 \mathrm{a}$ & $67,30 \mathrm{a}$ & $67,94 \mathrm{a}$ & 2,38 \\
Gordura (\%) & $23,18 \mathrm{~b}$ & $24,22 \mathrm{~b}$ & $27,70 \mathrm{a}$ & $29,01 \mathrm{a}$ & 11,30 \\
Cinzas (\%) & $11,18 \mathrm{a}$ & $10,78 \mathrm{a}$ & $10,55 \mathrm{a}$ & $9,66 \mathrm{a}$ & 10,02 \\
Proteína (\%) & $61,60 \mathrm{a}$ & $60,10 \mathrm{a}$ & $54,59 \mathrm{~b}$ & $58,47 \mathrm{a}$ & 4,70 \\
\hline
\end{tabular}

${ }^{1}$ Médias seguidas de letras iguais, na mesma linha, não diferem estatisticamente entre si pelo teste de Scott e Knott ao nível de 5\% de significância.

Esses resultados concordam com os de Araújo (1999) que, trabalhando com tilápias (Oreochromis niloticus Linnaeus, 1766), observou efeito nãosignificativo para GPDM (ganho de peso diário médio), GPTM (ganho de peso total médio) e GPFM (ganho peso final médio), mas para CARM (consumo aparente ração médio) e CAA (conversão alimentar aparente) foram estatisticamente significativos $(\mathrm{P}<0,05)$, o que não ocorreu no presente experimento. Esse resultado diferente pode estar relacionado ao grande controle de consumo de ração que foi realizado durante o período experimental, utilizando um cocho adaptado para evitar a perda, o que não ocorreu com Araújo (1999), que forneceu ração "ad libitum".

As médias de umidade, gordura (extrato etéreo), cinzas (matéria mineral) e proteína corporal dos peixes, nos diferentes tratamentos, estão apresentadas na Tabela 3. Essas médias foram comparadas pelo teste de Scott e
Knott, sendo as diferenças não-significativas para umidade e cinzas $(P>0,05)$. As únicas análises que apresentaram um efeito significativo $(\mathrm{P}<0,05)$ foram para proteína e gordura.

Os tratamentos contendo milho extrusado e milho moído apresentaram uma maior deposição de proteína e um teor de gordura estatisticamente menor $(\mathrm{P}<0,05)$. Nesses tratamentos, foi possível aumentar a utilização da proteína como fonte estrutural e não como fonte de energia. Araújo (1999), trabalhando com milho extrusado para juvenis de tilápia do Nilo (Oreochromis niloticus Linnaeus, 1766), obteve resultados semelhantes, com teor de proteína estatisticamente maior e o teor de gordura menor $(\mathrm{P}<0,05)$, mostrando ser possível aumentar a utilização da proteína para deposição na carcaça. Entretanto, os dados do presente trabalho divergem de Shiau (1997), que encontrou valores não-significativos para a composição de carcaça dessa espécie, nas mesmas condições. 


\section{CONCLUSÕES}

Pelos resultados, conclui-se que o processamento térmico empregado na extrusão e peletização do milho permitiu uma melhor utilização do amido para fins energéticos e da proteína para a deposição em tecidos. Entretanto, nas condições em que foi realizado o experimento, esses processamentos não proporcionaram melhoria significativa no aproveitamento dos carboidratos pela piaba (Leporinus friderici Bloch, 1794), não interferindo, portanto, no seu desempenho.

\section{REFERÊNCIAS BIBLIOGRÁFICAS}

ARAÚJO, M. G. Influência de rações formuladas com milho processado e amido de milho sobre o desempenho e composição corporal da tilápia (Oreochromis niloticus Linnaeus, 1757). 1999. 44 p. Dissertação (Mestrado Zootecnia) - Universidade Federal de Lavras, Lavras, 1999.

ASSOCIATION OF OFFICIAL AGRICULTURE CHEMISTS. Official methods of analysis of the Association of Official Agriculture Chemists. Washington, 1990. 1102 p.

COELHO, S. R. C. Situação atual e perspectivas da indústria de rações para organismos aquáticos. In: SIMPÓSIO SOBRE MANEJO E NUTRIÇÃO DE PEIXES, 1997, Piracicaba. Anais... Campinas: CBNA, 1997. p. 102-116.

FERREIRA, D. F. SISVAR - Sistema de Análise Estatística. Lavras: UFLA, 2000.

FIALHO, E. T. Qualidade dos dados em uma base de dados: subsídio para elaboração de uma tabela nacional de alimentos para suínos e aves. In: REUNIÃO ANUAL DO COLÉGIO BRASILEIRO DE NUTRIÇÃO ANIMAL; WORKSHOP BANCO DE DADOS SOBRE COMPOSIÇÃO DE ALIMENTOS, 1997, Campinas. Anais... Campinas: CBNA, 1997. p. 89-114.

GATLIN, D. M. Nutrition and feeding of red drum and hybrid striped bass. In: CHAND; WANG, S. S. (Eds.). Advences in extrusion technology. Lancaster: Technomic, 1999. p. 43-52.

HILTON, J. W.; ATKINSON, J. L. Responce of rainbow trout (salmo gairdner) to increased levels of avaible carbohydrate in practical trout diets. British Journal of Nutrition, Cambridge, v. 47, p. 597-607, 1982.
JAYARAM, M. G.; SHETTY, H. P. C. Formulation, processing and water stability of two new pellted fish feeds. Aquaculture, Amsterdam, v. 23, p. 355-359, 1981.

KUBITZA, F. Nutrição e alimentação dos peixes cultivados. Campo Grande, MS: [s.n.], 1998. 108 p.

MILLÁN, L. M.; HERRERO, A. V.; GUERRERO, I. C. Tecnologia de fabricación de piensos para la acuicultura. In. MONTEROS, J. E. de los; LABARTA, U. Alimentacion en aquicultura. Madri: Comissión Asesora de Investigación Científica y Técnica, 1987. p. 131-166.

NAS/NRC. Nutrient requirements of warmwater fishe and shellfishe. Washington: National Academy of Sciences, 1993. 171 p.

NOMURA, H. Dicionário dos peixes do Brasil. Brasília: Editerra, 1984. 482 p.

PEZZATO, L. E. Ração de qualidade gera melhor resultado. Alimentação Animal, São Paulo, ano 2, n. 5, p. 26-28, 1997.

SHIAU, S. Y. Utilization of carbohydrates in warmwater fish: with particular reference to tilápia, oreochromis niloticus x 0 . aueus. Aquaculture, Amsterdam, v. 151, p. 79-96, 1997.

SHIMENO, S.; HOSOKAWA, H.; HIRATA, H.; TAKEDA, M. Comparative studies on carbohydrate metaboism of yellotail and carp. Bulletin Japanese Society Science Fish, Tokio, v. 43, n. 2, p. 213-217, 1977.

SULLIVAN, J. A.; REIGH, R. C. Apparent digestibility of selected feedstuffs in diets for hybrid striped bass (Morone saxatilis x Morone chrysops). Aquaculture, Amsterdan, v. 138, p. 313-322, 1995.

TAKEUCHI, T.; JEONG, K. S.; WATANABE, T. Availability of extruded carbohydrate ingredients to rainbow trout oncorhynchus mykiss and carp cyprinus carpio. Bulletin Japanese Society Science Fish, Tokio, v. 56, n. 11, p. 1839-1845, 1990.

UMMINGER, B. L. Naturwiissentsch. [S.l.: s.n.], 1978.

WILSON, R. P. Reviw: utilization of dietary carbohydrate by fish. Aquaculture, Amsterdam, v. 124, p. 67-80, 1994. 
